\author{
Military Technical College \\ Kobry El-Kobbah, \\ Cairo, Egypt
}

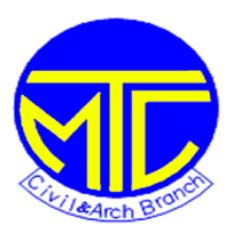

$12^{\text {th }}$ International Conference on Civil and Architecture

Engineering

ICCAE-12-2018

\title{
Application of Ground Penetrating Radar (GPR) technique to detect and analyse the geotechnical state of the water constructions and installations.
}

\section{M.A. Atya \\ National Research Inst. of Astronomy \& Geophysics, Helwan, Egypt.}

\section{Abstract:}

The ground penetrating radar is the top technology of the near surface investigation of the soil. Applying the radar frequency bands (high to low) help to inspect the soil and subsoil textures from the super shallow depths to the considerable depths mostly requested by the geotechnical and constructional assessments. Depending on the depth and the case subjected, it helps to detect and probably monitor the concrete voids and concrete steel deformation in, bridges top-plate and the barrier columns, tunnels, cavities, etc.

Water constructions and installations could be the most complicated tasks where the other geophysical techniques, probably but GPR, mightn't be capable to be conducted. In here, we show the contribution of the GPR techniques to evaluate and post a solution on some geotechnical problems in the water installations.

Siphons are water structures constructed when a draining line intersect with a channel or a canal, in this case the drainage would be piped and installed to pass underneath the channel. Although the structural designs of siphons could be counted, a big lack of information about these designs is missing. Normally, bridges and roads are constructed over these siphons to make the community cross over the channel sides, but in some cases, it is much more complicated, for example when a rail way passes over the siphon, or when the siphon should cross underneath wide water paths. Within this part of the 
application, the GPR was utilized to inspect and analyze the geotechnical situation and provide real contribution to solve the specific problems.

Subsidiary Channel's installations; the subsidiary channels are smaller channels constructed on the sides of big channels or canals, they would be used to distribute water to the lands on the sides and most important to regulate the irrigation process. In some cases, the extensive motion and activity in the big canals cause erosion on the inner shores resulting the shrinking of the road widths on the two sides, other cases, when the heavy traffic duty, probably truckers and heavy machines, or just re-design requires the widening of the roads and in turn cover the subsidiary channels. The constructional elements are pipes, inspection rooms, and valve houses. The GPR was used in more than a phase of this process such as inspecting the pipe states, the twists, the inspection room deformations, and the covering soils before paving.

\section{Introduction:}

The applications of the ground penetrating radar are growing fast and touching several technical and environmental tasks. Its contributions to solve the geotechnical problems and it non-destructive nature put it on the top level of the near surface investigating devices. The wide frequency range used in the GPR systems makes it capability to probe varieties of investigation depts.

In the present work, we show the results of investigating some specific technical problems related to water installations of different types. Drains siphons are constructions to make the drain intercourse with a channel or irrigation course, it has been studied in several places and we report probably two cases of the siphon together with the results conducted on a subsidiary covered irrigation channel. 


\section{Ground Penetrating Radar GPR}

A ground penetrating radar system includes a transmitter, a receiver and a data collection device (Fig.1). The transmitter sends a radio signal from an antenna into surrounding space. The receiver picks up reflections received from this radio signal, the strength and direction of the reflected signal give indications for the size and distance to reflecting object(Daniels, 1996).

A major advantage of GPR is that it records vertical soil profiles in detail, rather than generating only horizontal plan maps. It must be remembered that GPR doesn't directly image objects in the ground: it produces a two-dimensional record of the three-dimensional waves bouncing of object in the ground (Davis et

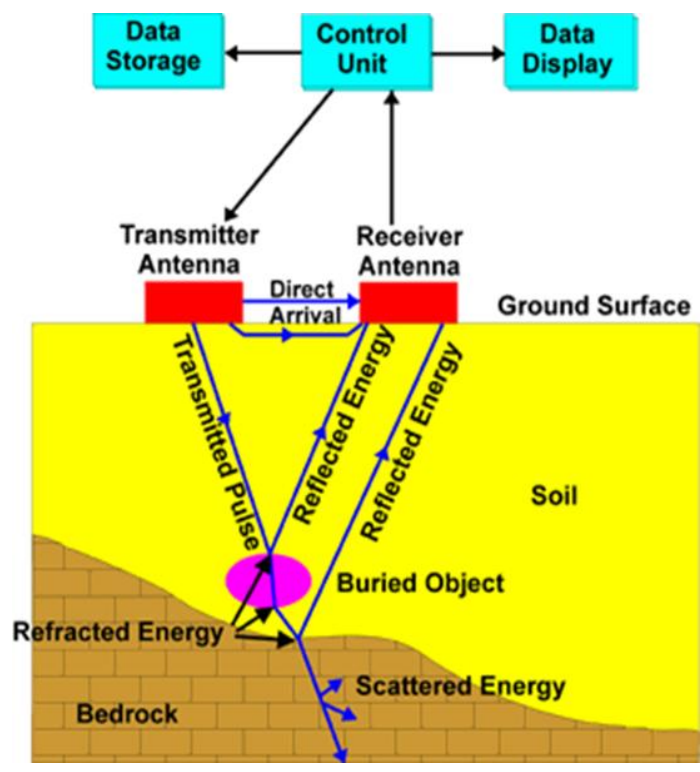

Fig. (1): GPR schematic, from EPA (Environmental Protection Agency, web site). al.,1989). Linear features which are aligned with the GPR's electrical field will not produce high reflectance values. However, this means that GPR is good at distinguishing linear features only if they run perpendicular to the path of the antenna (Sharma Prem, 1997).

\section{Case 1: Edko Drain's Siphon:}

This case represents an anatomical investigation of the siphon constructed to allow the water of
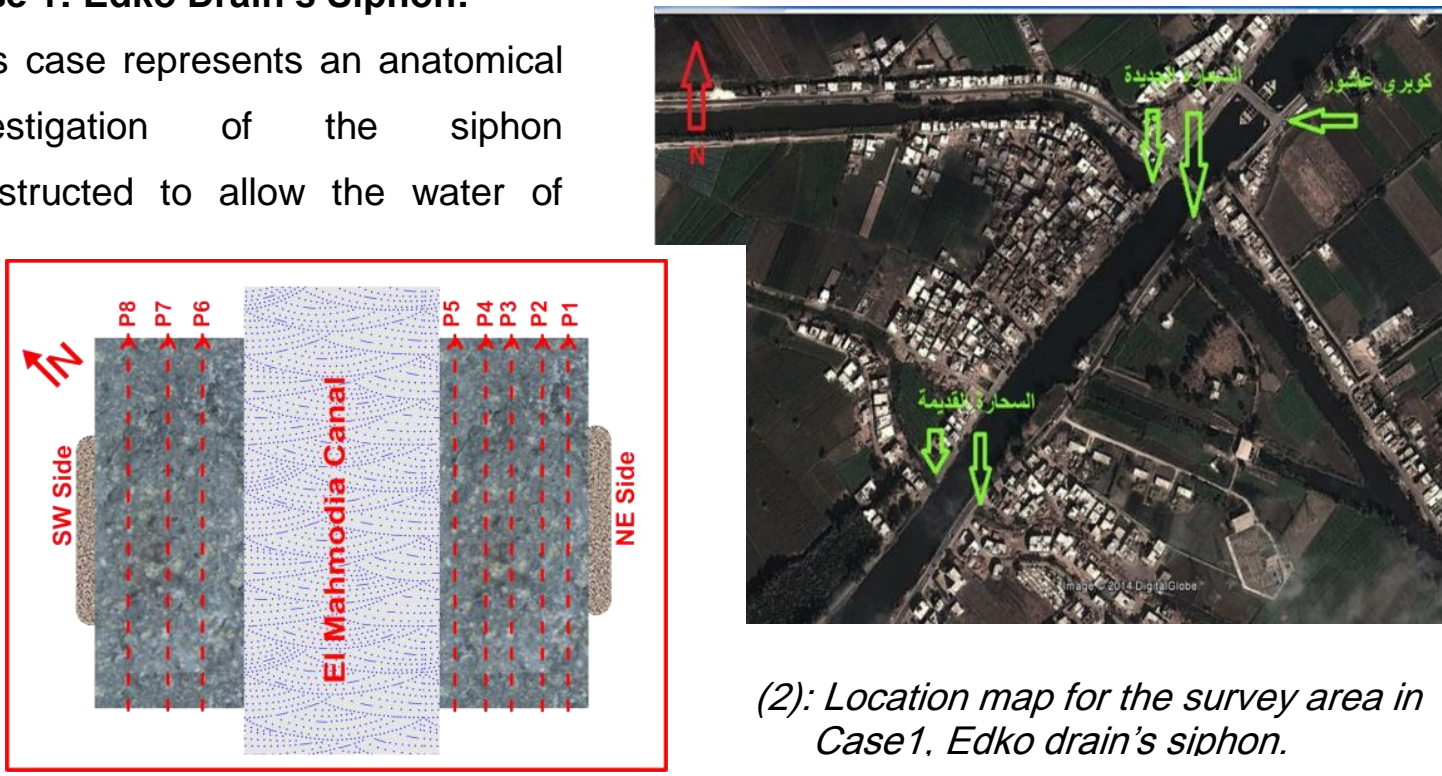

(2): Location map for the survey area in Case1, Edko drain's siphon.

Fig. (3): the GPR profiles directions over the covered drainage body. 
Edko drain to pass underneath Al-Mahmoudia Channel, figure (2) describes the location. it shows two intersections for Edko drain with Al Mahmoudia channel, the old one in the south and the newer one in the north. The two siphons were studied but the newer one in the north will be described here. Eight GPR lines were conducted using the SIR 10A system connected with the $200 \mathrm{MHz}$ antenna (Fig. 3). We set up the system to collect a GPR scan every 2 centimeters (50 scans per meter) and condensed the reads to 1024 sample per scan. The siphon's mouth "entrance" located beneath the NE side as the siphon's exit located beneath SW side. Five lines were conducted on the mouth and three on the exit. We introduce the tow lines 7 and 8 on the SW side of siphon's exit where the damage appears obviously, the bridge was subsided and the shoulder was cracked. The GPR survey helped to visualize the fissures and cracks of the bridge's body and shoulders. Applying the GPR signature (Fig. 4) shows that some of the cracks and distortions could be traced from the surface. Further to that, the siphon's body could be imaged and evaluated to good state in most of its parts at the exit. Distortions on few parts were reported to the concerned authority with detail maps and discriptions.
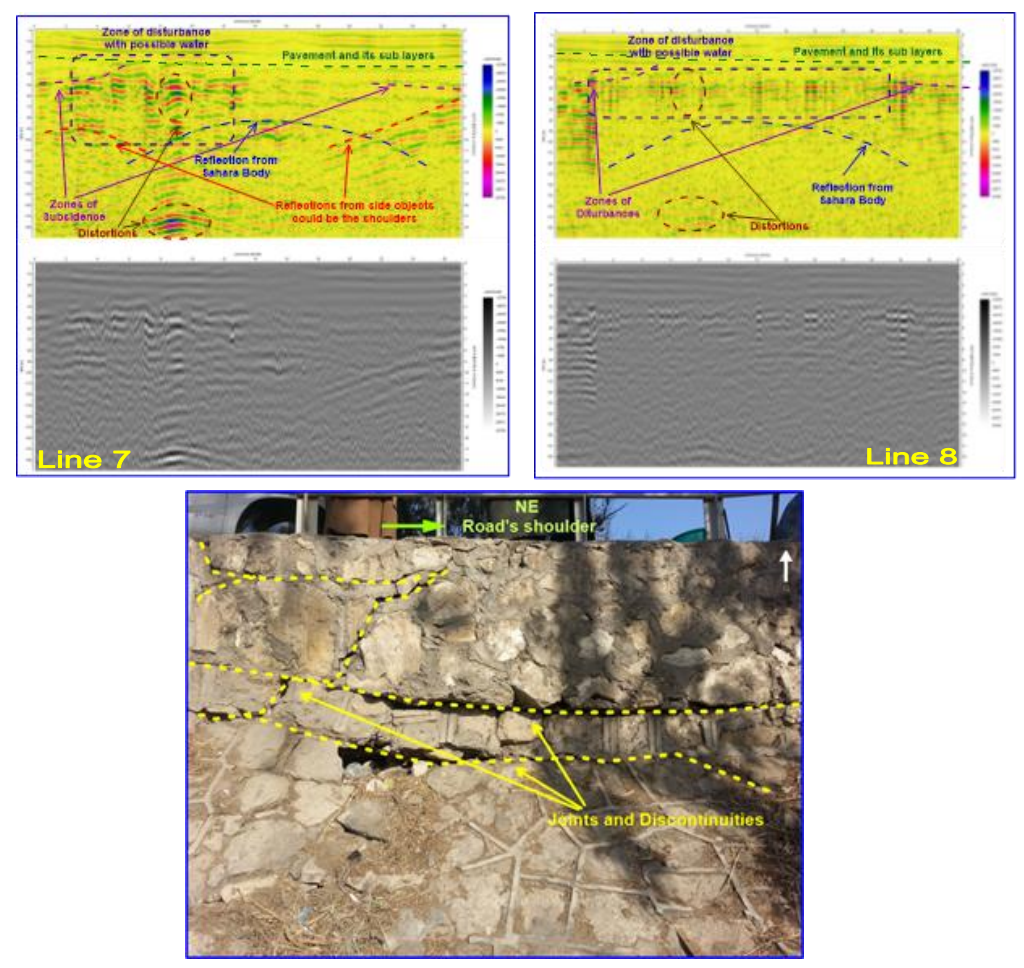
Fig. (4): the GPR lines 7 and 8 on the top in color and grey scales while the lower one shows the shoulder of the siphon.

\section{Case 2: Subsidiary Irrigation Channel Coverage:}

Within this case, the ground penetrating radar was used to control the quality and component's consistency of all the process elements. Figure (5) shows the items proposed for investigation; these are; the concrete pipes of 1.5 meters diameter and 3.5 meters length, the yield zone between each two pipes, inspection room, contactor's roadbed, and the roadbed made by the authority of roads and bridges. Further to that the survey structures that composed of three lines between each two inspection rooms. Two diagonals intersecting close to the middle and the third runs exactly
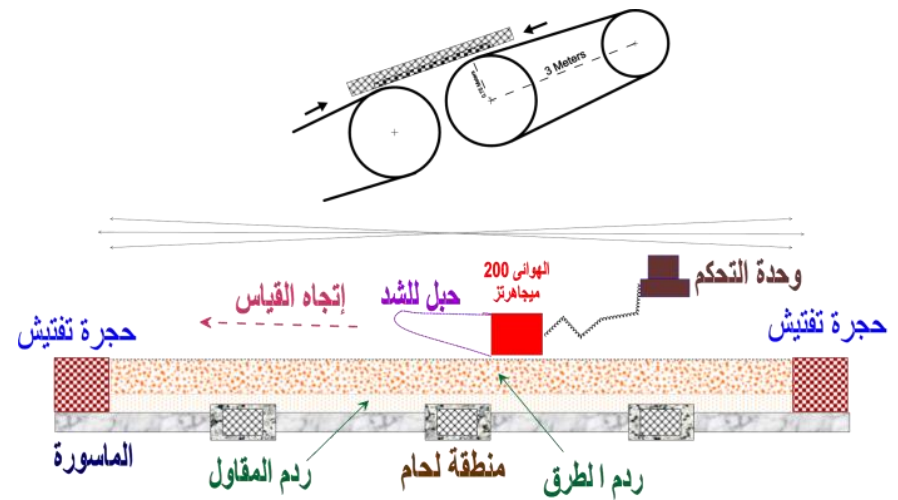

Fig. (5): the items subjected for inspection by GPR and the survey protocol.

over the pipe's body. In the following we show the results and GPR signature records over the different items of control process. Figure (6) shows the pipe body, yield positions, and contractor's roadbed.
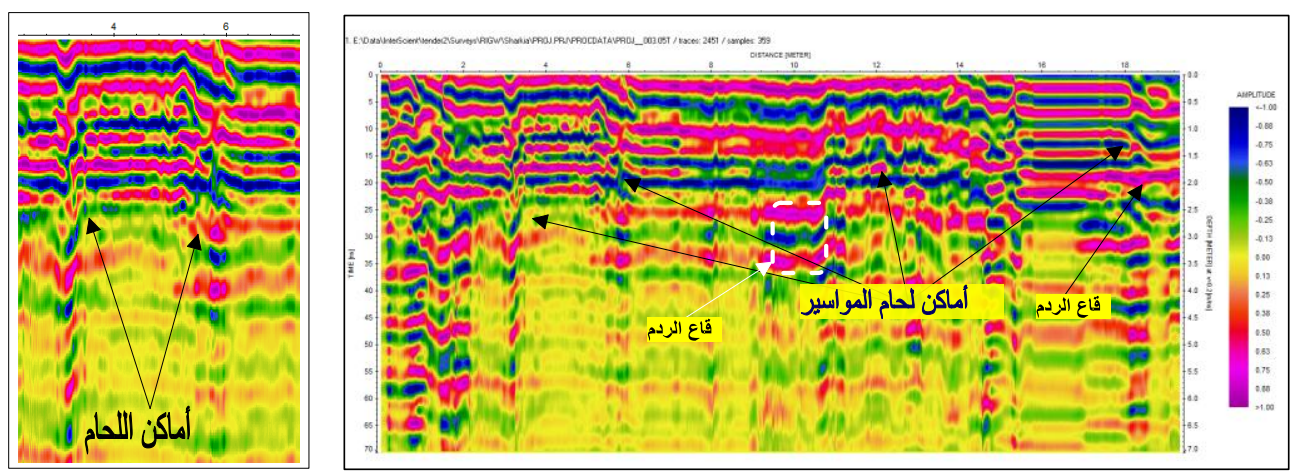

Fig. (6): the items subjected for inspection on GPR record. 


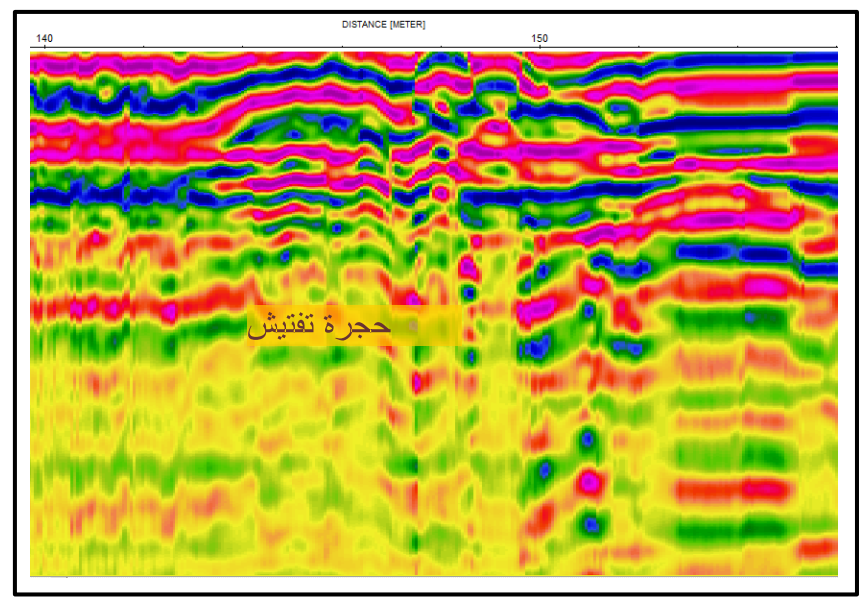

Fig. (7): Inspection room with construction's defections.

Figure (7) provide the GPR signature for the inspection room, it shows defections on the right side of the room, it is obvious that the defects resulted from a rock subsidence on the right side just before the right side of the inspection room.

\section{Conclusion}

The GPR measuring technology and the enhanced techniques of processing and interpretation jumped with the method widely to contribute in solving the geotechnical problems. It proofed its capability to interact and positively share in detecting the near surface subsidence in roads, siphon's defects and distortions, bridge's falls and many other geotechnical problems.

\section{Acknowledge}

The author thanks deeply the field helping teams from NRIAG and RIGW.

\section{References}

Benson, A. K., 1995: Application of ground penetration radar in assessing some geological hazards: examples of groundwater contamination, fauls, cavities."J. of Applied Geophysics, 33 (1-3) 177-193.

Beres, M., and Haeni, F. P., 1991: Application of ground-penetrating radar method in hydro geologic studies. "Groundwater, 29 (3) 375-386.

Daniels, D. J., 1996: Surface-penetrating radar, in, IEEF Radar, Sonar, Navigation and Avionics Series 6, E. D. R.

Davis, J.L., and Annan, A.P., 1989: Ground-penetrating radar for high-resolution mapping of soil and rock stratigraphy. Geophysical prospecting, v.3e7, P. 531-551. 
Davis, J.L., and Annan, A.P., 1989: Ground-penetrating radar for high-resolution mapping of soil and rock stratigraphy. Geophysical prospecting, v.3e7, P. 531-551. 